\title{
Towards taxonomy's 'glorious revolution'
}

\section{Taxonomy is a triumph of modern science — but its products could still be improved.}

Sir-My commentary "Challenges for taxonomy" (Nature 417, 17-19; 2002), in which I argued for unitary, web-based taxonomies, has stimulated a lively debate. In Correspondence, K. Thiele and D. Yeates (Nature 419, 337; 2002) make the important point that, unlike stars or genes, species and other taxa are hypotheses, not facts. A taxonomic name is thus a shorthand for this hypothesis, but it is also the key that indexes all the biological information on that taxon.

I agree wholeheartedly that any unitary taxonomy must recognize this duality. That is why I suggested that while the 'current web revision' would present only a single taxonomy for the user community, any alternative hypothesis would by right be lodged on the website and possibly enter a future revision. I believe a unitary taxonomy can be authoritative without being authoritarian.
In another Correspondence, I was disappointed that the high command of London's Natural History Museum found so little merit in these ideas (S. Knapp et al., Nature 419, 559; 2002), but I fear I must have explained them poorly. I do not seek to "throw out the past mechanisms of doing systematics and begin anew in a revolutionary 'brave new world'”, nor to do away with the order and stability conferred by type specimens, nor to belittle the major taxonomic web projects already in existence. I think we should tinker as little as possible with the process of taxonomy, although my proposals for the products of taxonomy are more radical. However, exploring whether they might work for one group or for a few groups is only a small, reversible step.

Taxonomy as currently practised works and we need much more of it. It is one of the triumphs of modern science. But unless it looks to its end-users and provides them with products that they will both use and actively campaign for (and I believe this can be done while maintaining the subject's core methodology), I worry deeply that it will lose out in the intense competition in the sciences for funds.

I wrote that one of the advantages of unitary taxonomies is that they are "evolutionary, not revolutionary", and so was amused to be labelled a revolutionary. But there are revolutions and revolutions, and while taxonomy does not need the 1789 French version with its ensuing reign of terror, perhaps it does need something like England's ‘Glorious Revolution' of 1688.

H. C. J. Godfray

NERC Centre for Population Biology, Imperial College at Silwood Park, Ascot, Berkshire SL5 7PY, UK

\section{US embryo rules support 'right-to-life' agenda}

Sir - I believe that the crisis facing embryo research in the United States is a great deal more serious than your news item "US biologists wary of move to view embryos as human beings" (Nature 420, 3-4; 2002) portrayed it. The Bush administration's clear intent is to establish a legal precedent for declaring embryos to be people from the moment of conception. If this effort succeeds, all research on embryos in the United States could cease.

Assurances that the changes are intended only to protect pregnant women are obvious falsehoods. If that were the case, the new remit would emphasize "pregnant women", not "pregnant women, embryos, and fetuses". These assurances have been made by the deputy assistant secretary of the Health and Human Services (HHS) department, Arthur Lawrence, reported in The Washington Post (30 October 2002, page A1), as well as by HHS spokesman Bill Hall, as reported in your News story. Any doubts about the political motivation of these changes should be settled by the Bush administration's stated intention, also reported in The Washington Post's article, to place on the new HHS committee Mildred Jefferson - a founder and past president of the National Right to Life Committee.

Adherents of the US 'right to life' movement have made backdoor attempts at legislation before. A proposal to declare conception as the beginning of legal personhood by constitutional amendment has been floating around for many years. Even the amendment's supporters concede that it has no chance of ratification, however, so attempts proliferate to obtain by executive fiat that which is unobtainable by straightforward appeal to US citizens. Given the results of the 5 November elections, we can expect more such attempts in the near future.

The biomedical community and patients' advocacy groups should harbour no illusions about what is at stake. The goal of certain elements in US politics is to have balls of undifferentiated cells legally defined as people. From that beginning, the argument that a ball of cells cannot give informed consent, and therefore cannot be a test subject, is a short and inescapable step away.

Gordon G. Cash

Address supplied

\section{Would you give up your grant for sustainability?}

Sir - Your Opinion editorial "Leadership at Johannesburg” (Nature 418, 803; 2002) reveals delusions about the sustainabledevelopment summit. Most scientists care little about sustainability, and very few work towards achieving it. I have tried to excite the geoscience community's interest, for example (Geoscientist 11, 1 (15) and 5 (11); 2001), but elicited only a meagre response.

You write of poverty alleviation, improved (renewable) energy generation and better water supplies in developing countries. Less poverty leads to greater consumption of goods and services, of energy, water, land and so on. That is not sustainable development. The Correspondence by E. D. G. Fraser and W. Mabee (Nature 418, 817; 2002) correctly predicted that the summit would fail, but shed no new light on the issues.

Which of the following do readers consider compatible with sustainable development? Expanding airports and road networks, growing car and aviation industries (including motor racing)? The international arms trade? Logging of rainforests? Trapping and shooting of endangered birds and animals? Overfishing and progressive pollution of the oceans? Inability to police environmental legislation anywhere in the world? Corruption at all levels of government throughout the world?

In a piece entitled "Sustainable development unsustainable” (Nature 374, 305; 1995), John Maddox wrote an approving review of Wilfred Beckerman's book Small is Stupid. Beckerman was wrong to imply that Earth's resources are not finite, but he and Maddox were right to point out that we need economic growth.

Can anyone name a country, rich or poor, where sustainable development is a central plank of government policy? Sustainable development means living in equilibrium with natural cycles. That means reduced consumption, which very few people want. Any attempt to wean industrial civilization off fossil fuels would lead to instant global recession and 
economic decline. Without economic growth there would be no profits, hence no taxes, no public services, no pensions or state benefits - and no research grants! John Wright

Department of Earth Sciences, Open University, Milton Keynes MK7 6AA, UK

\section{DNA committee is model for bioterrorism debate}

Sir - There is much debate about how to protect the public from bioterrorism while maintaining the open exchange of biomedical research findings (see, for example, Nature 419, 99 and 769; 2002). There have been several calls by scientists and science journalists in the media for a 'summit conference' to discuss these concerns and to establish a US national forum to guide federal policy on scientific research with possible bioterrorism applications.

Fortunately, a highly effective model already exists. The 1975 Asilomar conference led to the establishment of the NIH Recombinant DNA Advisory Committee (RAC) to provide guidance and oversight of research using recombinant DNA (see, for example, R. M. Atlas Science 298, 753-754; 2002).

Piecemeal regulation will harm the advancement of science and wreak havoc on national security. Already the US Office of Management and Budget is planning to draft rules on the publication of some federal research classified as "sensitive homeland security information", but these rules will apply only to US government laboratories. In testimony before the House of Representatives Science Committee, several university officials said the proposed new rules would not serve the best interests of science.

A broadly based committee modelled on the RAC should be established now under the aegis of the NIH to develop guidelines for biomedical research with possible bioterrorism applications. A comparable committee should be formed in the US Department of Agriculture to deal with agricultural research. An interagency coordinating committee would be needed for supervision on security concerns related to governmentsponsored research.

An agenda for an RAC-like committee has been laid out by questions raised since last year's anthrax attacks. First, should access to genome databases be restricted? Would such restrictions prevent bioterrorism? More than 60 microbial genomes have already been deposited in publicly available genome databases and work is actively progressing on more than
150 more, as well as on several parasitic, fungal, plant and insect genomes.

Second, should scientists and scientific publishers practise self-censorship? For example, we now know that live poliovirus can be synthesized and that mail-order companies will provide the building-blocks necessary to reconstruct the virus in a laboratory. What, if any, restrictions on the publication of scientific findings are legitimate?

Third, should the training of scientists in the United States, whether US citizens or foreign nationals, be restricted? New US legislation requires universities and laboratories dealing with "select agents" to be registered with the US Department of Health and Human Services or the US Department of Agriculture and requires individual scientists to submit to background checks by the Department of Justice. Will an increasingly perilous legal landscape discourage legitimate scientists from engaging in research on infectious diseases?

The RAC model has served us well in the past; we should use it as the starting point for addressing these key policy questions to achieve effective and optimal guidance for the future.

Joseph G. Perpich

JG Perpich, LLC, 7315 Wisconsin Avenue, Suite 500

East, Bethesda, Maryland 20814, USA

\section{Modelling a new angle on understanding cancer}

Sir - There was a striking absence of discussion of quantitative methods in the recent interesting theoretical debate on the timing and nature of mutations controlling acquisition of the metastatic phenotype in invasive cancers (R. Bernards and R. A. Weinberg Nature 418, 823; 2002 and Correspondence Nature 419, 559-560; 2002). Without the discipline imposed by mathematical rigour, the arguments have to rely on intuitive reasoning and small pieces of data singled out from the vast extant literature. The reader is unable to independently evaluate the hypotheses or understand them in the context of all available experimental information or of theoretical models that organize information in integrally related phenomena such as carcinogenesis and tumour invasion. Although this state of affairs is normal in some disciplines such as tumour research, it would be unthinkable in the physical sciences.

Medical investigators often eschew mathematical models as too "simplistic" for the dynamics governing processes such as those in tumour biology. Instead, the general underlying principles in complex biological processes are expected to become apparent, as if by magic, once sufficient data are accumulated. Not surprisingly, this passive approach has failed to yield a comprehensive theoretical framework of understanding carcinogenesis, tumour invasion and metastatic behaviour. Clinical therapy thus remains largely empirical, based more on trial and error than a comprehensive understanding of biological first principles.

In most other scientific disciplines, there is an active search for broad generalizations through hypotheses framed in mathematical models that can be examined for internal consistency and compatibility with extant data. Predictions from these models can be tested by experiment and revised when necessary. Surely the success of this integrative approach, combining quantitative theoretical methods and experiment in highly complex systems in physics (including biophysics), chemistry, engineering and biological disciplines, such as ecology or structural biology, should motivate its enthusiastic application to other nonlinear biological processes such as carcinogenesis and tumour invasion.

In the absence of consistent application of rigorous mathematical models, theoretical medicine will largely remain empirical, phenomenological and anecdotal, successful only in linear systems that can be defined by a single experiment or a few experiments. Until the quantitative methods of the physical sciences are applied, many difficult and clinically important problems in tumour biology, including the dynamics that give rise to the metastatic phenotype, will remain unresolved. Robert A. Gatenby ${ }^{\star}$, Philip Maini $\dagger$ * Departments of Radiology and Applied Mathematics, University of Arizona, 1501 Campbell Avenue, Tucson, Arizona 85724, USA $\dagger$ Centre for Mathematical Biology, Mathematical Institute, 24-29 St Giles', Oxford University, Oxford OX1 3LB, UK

\section{Deserted by our geographical sense}

Sir - Your News in Brief on the Atacama Large Millimeter Array in Chile (Nature 419,$870 ; 2002$ ) sets a new record for imprecision. Chile is a narrow ribbon, with an average width of just $180 \mathrm{~km}$ and an eastern frontier of about $6,000 \mathrm{~km}$ of virtually constant longitude. Hence, referring to the observatory as located: "in the Atacama desert in the east of the country" is definitely too indefinite for anyone wanting to find it.

Gustavo Arteca

Département de Chimie et Biochimie, Laurentian University, Sudbury, Ontario P3E 2C6, Canada 